\title{
Analisis perbandingan pengaruh store atmosphere terhadap loyalitas pelanggan coffee shop di Bandung
}

\author{
Christian Bernard Gunawan* \\ Program Studi Administrasi Bisnis Universitas Telkom \\ J1. Telekomunikasi Terusan Buah Batu Bandung \\ christianbernard996@gmail.com \\ Syahputra Syahputra \\ Program Studi Administrasi Bisnis Universitas Telkom \\ Jl. Telekomunikasi Terusan Buah Batu Bandung \\ syahputra@telkomuniversity.ac.id \\ *Penulis Korespondensi
}

Submitted: Sept 12, 2020; Reviewed: Sept 15, 2020; Accepted: Oct 07, 2020

\begin{abstract}
Nowadays, increasing in the Indonesia coffee industry, especially in Bandung city, is more interesting to be researched more deeply. This research was conducted to determine store atmosphere and customer loyalty at coffee shops in Bandung city, how much impact it has, also there is a difference in customer loyalty at coffee shops in Bandung city. In this research, researchers use a quantitative method, with the type of research is descriptive-causality. Sampling was used non-probability method, with purposive sampling type, by 20 respondents in each of the five coffee shops. By using descriptive analysis, simple regression analysis, and one-way ANOVA methods, the results show that store atmospheres significantly affect customer loyalty at coffee shops. Besides that, this research found that store atmospheres have an effect of $38,8 \%$ on customer loyalty and other factors that do not in this research effect of $61,2 \%$. This research also shows that there is no difference in customer loyalty at coffee shops. Researchers concluded that store atmosphere and customer loyalty at these five coffee shops in Bandung, already included in the excellent category. However, these five coffee shops need to lead a different uniqueness from the side of store atmospheres. This matter is necessary, so customers feel a different store atmosphere from others, thus becomes the uniqueness of coffee shops. This research expects to provide input for five coffee shops that researched and coffee shop entrepreneurs, as well as being information for further study.
\end{abstract}

Keywords: coffee shop; customer loyalty; store atmosphere

Abstrak: Perkembangan industri kopi di Indonesia saat ini, terutama di kota Bandung, menjadi kian menarik untuk ditekuni lebih dalam. Penelitian ini dilakukan untuk mengetahui suasana toko dan loyalitas pelanggan pada coffee shop di kota Bandung, seberapa besar pengaruhnya, serta apakah ada perbedaan loyalitas pelanggan pada coffee shop di kota Bandung. Dalam penelitian kali ini, peneliti menggunakan metode kuantitatif dengan jenis penelitian yaitu deskriptif-kausalitas. Pengambilan sampelnya dilakukan dengan metode non-probabilty sampling, purposive sampling, dengan jumlah responden dalam penelitian ini sebanyak 20 orang di tiap lima coffee shop. Dengan menggunakan metode analisis deskriptif, analisis regresi sederhana dan one way anova, hasil penelitian menunjukkan bahwa suasana toko berpengaruh signifikan terhadap loyalitas pelanggan di coffee shop. Selain itu, ditemukan bahwa suasana toko berpengaruh sebesar 38,8\% terhadap loyalitas pelanggan, dan faktor lain yang tidak diteliti dalam penelitian ini berpengaruh sebesar 61,2\%. Penelitian ini juga 
menunjukkan bahwa tidak ada perbedaan loyalitas pelanggan di coffee shop. Peneliti menyimpulkan bahwa suasana toko dan loyalitas pelanggan pada lima coffee shop di Bandung, sudah termasuk ke dalam kategori sangat baik. Namun, lima coffee shop ini perlu menghadirkan keunikan yang berbeda dari sisi suasana toko. Hal ini diperlukan agar pelanggan merasakan suasana toko yang berbeda dari yang lain, sehingga menjadi keunikan dari coffee shop tersebut. Penelitian ini diharapkan dapat memberi masukan bagi lima coffee shop yang diteliti dan juga para pebisnis coffee shop, serta menjadi informasi bagi penelitian selanjutnya.

Kata kunci: kedai kopi; loyalitas pelanggan; suasana toko

\section{PENDAHULUAN}

Tingkat produksi kopi di Indonesia saat ini menempati posisi keempat terbesar di dunia. Hal ini karena Indonesia merupakan negara tropis, meskipun dilewati batas garis khatulistiwa, Indonesia juga punya daerah pegunungan yang cocok untuk menanam varietas kopi arabika. Di Indonesia, kopi memunyai peran penting bagi pertumbuhan ekonomi masyarakat. Dalam perkembangan zaman di Indonesia, telah terjadi perubahan trend yang mendorong peningkatan konsumsi kopi di kalangan masyarakat Indonesia. Peningkatan ini dapat dilihat dari Gambar 1 tentang grafik jumlah konsumsi kopi pada negara eksportir, yang menunjukkan tingkat pertumbuhan konsumsi kopi di Indonesia yang meningkat tiap tahunnya. Pertumbuhan konsumsi kopi di Indonesia setiap tahunnya, menempatkan Indonesia bertahan pada posisi kedua terbesar sebagai negara eksportir pengonsumsi kopi, dengan jumlah 4,55 juta karung kopi.

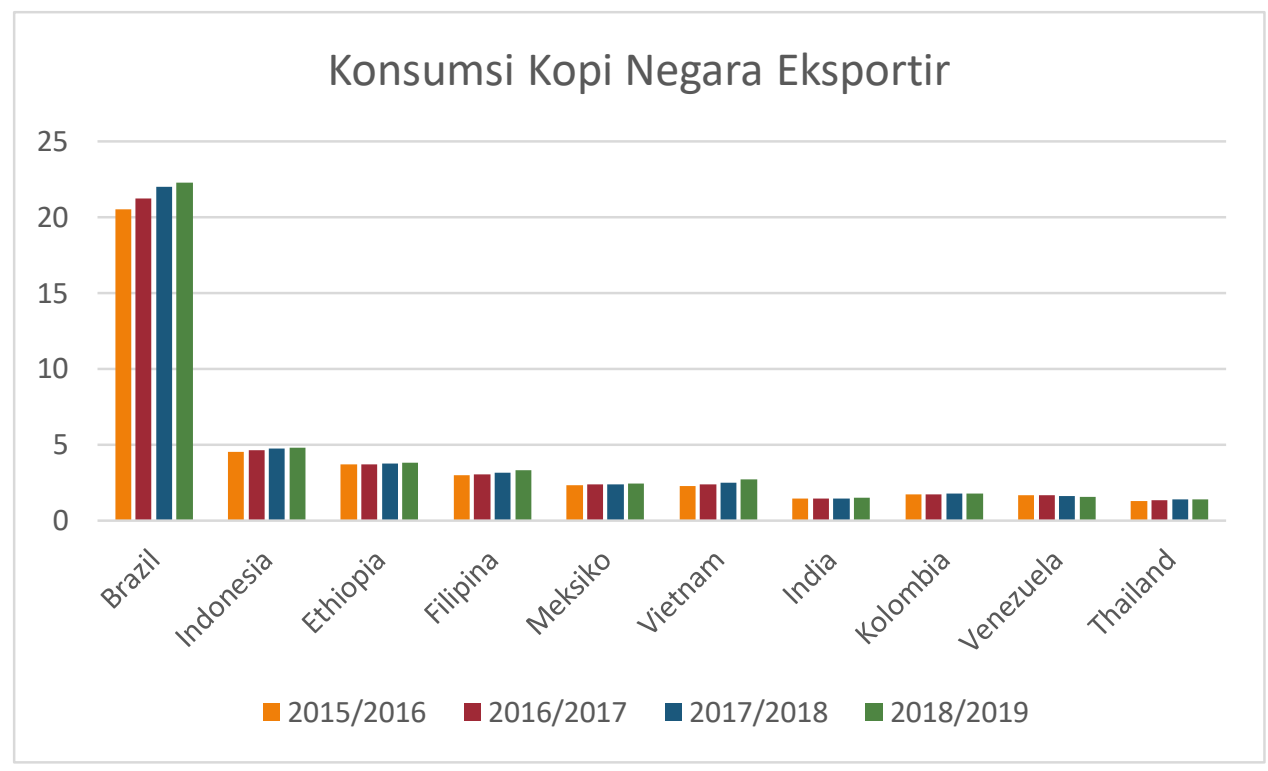

Gambar 1. Grafik jumlah konsumsi kopi pada negara eksportir Sumber: Pusparisa (2019)

Selain itu, jika ditelusuri lebih dalam dari Gambar 2 tentang grafik tingkat konsumsi kopi nasional Indonesia, dapat disimpulkan bahwa jumlah konsumsi kopi di Indonesia akan terus mengalami peningkatan. Dari Gambar 2 juga dapat dilihat bahwa konsumsi kopi di Indonesia sepanjang periode 2016-2021, jumlahnya diprediksi tumbuh rata-rata sebesar 8,22\% per tahun. Peningkatan konsumsi kopi di Indonesia dapat menyebabkan ekspor kopi Indonesia ke depannya kemungkinan turun. Hal ini didukung dengan pernyataan ketua GAEKI (Gabungan Asosiasi Ekpor Kopi Indonesia) bahwa terjadinya penurunan ekspor kopi karena adanya kenaikan konsumsi dalam negeri. Lebih lanjut, harga pembelian dalam negeri ini jadi lebih tinggi dibandingkan pembelian luar negeri (Sugandhi, 2019; dalam Larasati, 2019). 


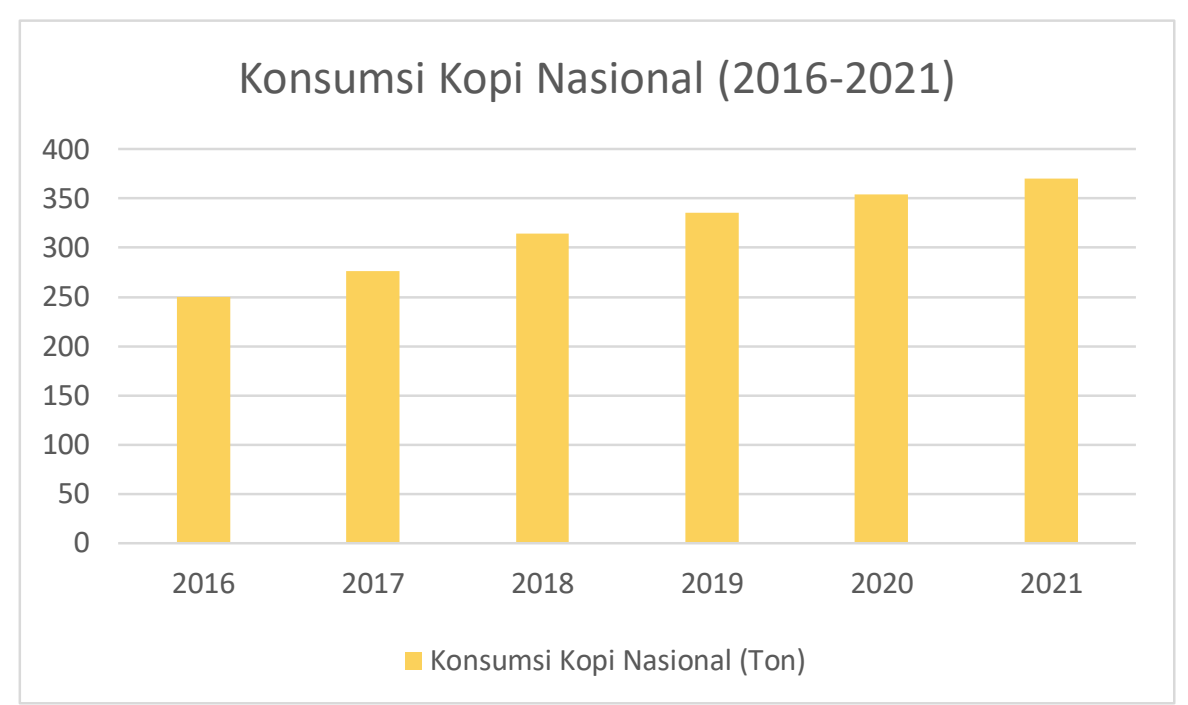

Gambar 2. Grafik konsumsi kopi nasional (2016-2021)

Sumber: Kementrian Pertanian (2017)

Walaupun tingkat ekspor kopi Indonesia turun, akan tetapi kepercayaan dunia terhadap Indonesia untuk mendorong kelangsungan ekonomi dari sektor industri kopi melalui kemitraan antara pemerintah dengan petani dan sektor industri masih tinggi. Hal ini membuat Indonesia dipercaya untuk memimpin International Coffee Organization (ICO) Council, yang diadakan pada 23-28 September 2019 di London, Inggris (Andri, 2019). Hal tersebut juga dapat membuktikan adanya pengakuan terhadap eksistensi (keberadaan) Indonesia terhadap kopi dunia atau pengakuan terhadap peran dan kontribusi Indonesia kepada organisasi internasional tersebut.

Berdasarkan Gambar 2 juga dapat disimpulkan bahwa meningkatnya konsumsi kopi nasional membuktikan bahwa ke depannya peluang bisnis coffee shop ini memiliki prospek bagus. Bisnis ini juga menjadi salah satu bisnis yang ke depannya menjanjikan keuntungan bagi para pelaku bisnis kopi. Hal ini dapat terjadi karena berkembangnya tren nongkrong dengan meminum kopi di kedai kopi atau coffee shop. Saat ini, meminum kopi tidak selalu identik dengan kegiatan yang dilakukan oleh bapak-bapak atau orang tua saja. Sekarang, di kalangan anak-anak muda pun meminum kopi menjadi gaya hidup mereka, dan juga sebagai sarana untuk menunjukkan eksistensi mereka terhadap teman-temannya. Perubahan pola hidup dari masyarakat sendiri membuat kedai kopi atau coffee shop tidak hanya berperan sebagai tempat untuk memenuhi kebutuhan pangan saja, akan tetapi sebagai tempat untuk memenuhi kebutuhan bersosialisasi, menongkrong dengan sesamanya.

Peluang pada industri kopi ini dapat tercermin dari jumlah pemuda di Indonesia. Dalam data yang ada di Survei Sosial Ekonomi Nasional oleh Badan Pusat Statistik di tahun 2018 dalam Monicasef (2019), penduduk dalam kategori pemuda ada sebanyak 63,82 juta jiwa. Angka tersebut adalah seperempat jumlah penduduk yang ada di Indonesia. Bila diamati dari jumlah pemuda tersebut, maka tren untuk mengonsumsi kopi di kalangan pemuda bisa menjadi potensi yang sangat besar untuk meningkatkan jumlah konsumsi kopi di Indonesia.

Di Indonesia sendiri banyak coffee shop atau kedai kopi yang berdiri, apalagi di kota metropolitan dan pusat kota, sangat mudah sekali untuk dijumpai. Salah satunya di kota Bandung, banyak kedai kopi atau coffee shop yang sedang berkembang. Sebuah artikel pada website Cosmopolitan Indonesia, merekomendasikan lima coffee shop atau kedai kopi di Bandung yang membuat nyaman untuk hang out, yaitu AC, K2, KK, SC, dan CB (Citta, 2019). Kelima coffee shop atau kedai kopi yang dicantumkan memiliki suasana yang membuat pengunjung nyaman untuk menongkrong, sambil menikmati hidangan kopi yang lezat. Walaupun terbilang baru, kelima coffee shop atau kedai kopi tersebut sudah diakui keberadaannya oleh masyarakat. Hal ini tercermin dari dimuatnya kelima coffee shop atau kedai kopi ini dalam artikel Cosmopolitan Indonesia.

Memiliki pelanggan atau pengunjung dengan loyalitas tinggi merupakan harapan bagi pemilik coffee shop atau kedai kopi. Meningkatnya loyalitas pelanggan terhadap produk yang ditawarkan, dapat memengaruhi business continuity di coffee shop tersebut. Hal ini karena pelanggan dengan loyalitas 
tinggi merupakan pelanggan yang memiliki kesetiaan untuk kembali dan menggunakan produk yang ditawarkan oleh coffee shop atau kedai kopi tersebut. Lebih lanjut, dengan meningkatnya jumlah konsumen yang datang dan menikmati produk tersebut, artinya jumlah konsumen yang membeli produk tersebut akan meningkat. Secara otomatis produk akan laku terjual, sehingga akhirnya laba yang akan diterima oleh coffee shop atau kedai kopi juga tinggi.

Namun, kini industri kopi Indonesia yang sedang meningkat, diikuti dengan menjamurnya bisnis ini di berbagai tempat dan kota yang ada di Indonesia. Banyaknya bisnis coffee shop yang berdiri di kota Bandung dapat menciptakan kondisi persaingan yang semakin ketat dan menuntut setiap pelaku usaha dalam bidang ini untuk mampu bersaing dan berinovasi di antara para kompetitornya. Saat ini, penggiat industri coffee shop perlu menginovasi konsep mereka menjadi lebih unik dan nyaman untuk didatangi, agar dapat menarik minat dan perhatian pelanggan, sehingga selanjutnya mereka dapat bersaing di dalam industri kopi. Jika produk dan harga yang ditawarkan dengan kompetitor kurang lebih sama, maka setiap pengusaha harus berupaya untuk dapat mendapatkan perhatian dan ketertarikan dari konsumen, sehingga ke depannya tercipta loyalitas pelanggan. Selanjutnya, hal ini tentunya dapat membuat pengusaha bisa memenangkan pasar. Hal ini penting untuk diperhatikan, karena loyalitas pelanggan ke depannya dapat menjadi masalah bagi pengusaha, jika tidak mempunyai keunikan dengan coffee shop atau kedai kopi lainnya. Store atmosphere bisa dijadikan salah satu alternatif untuk membedakan dengan coffee shop yang lainnya.

Ada bermacam-macam alasan yang dapat menjadikan faktor stimulus (rangsangan) kepada pengunjung untuk datang ke coffee shop atau kedai kopi. Akan tetapi, salah satu alasan untuk datang kembali ke coffee shop atau kedai kopi dan melalukan pembelian ulang adalah store atmosphere (suasana toko). Menurut Sujana (2012), store atmosphere dapat diartikan sebagai seluruh aspek-aspek interior (ruangan di dalam toko) yang berpengaruh terhadap suasana penjualan, terutama meliputi pemberian cahaya (lighting), warna (color), musik, dan wewangian. Store atmosphere dapat berpengaruh terhadap minat dari pengunjung yang datang, sehingga mereka datang kembali dan melakukan repurchase ke coffee shop atau kedai kopi. Selanjutnya, ketika pengunjung merasa senang, bahagia, puas, dan nyaman dengan suasana yang ada di coffee shop atau kedai kopi yang menerapkan store atmosphere, pengunjung akan memercayai tempat coffee shop atau kedai kopi tersebut, sehingga dapat menjadi penyebab kecenderungan melakukan pembelian secara berulang. Selain itu, pengunjung coffee shop atau kedai kopi akan menjadi loyal (setia) terhadap coffee shop atau kedai kopi.

Suasana coffee shop atau kedai kopi sekarang ini cenderung menggabungkan berbagai macam elemen dalam store atmosphere dan menjadikannya sebagai salah satu strategi coffee shop atau kedai kopi. Hal ini dilakukan untuk memengaruhi konsumen dalam keputusan pembelian, sehingga pengunjung dapat menjadi loyal untuk melakukan repurchase ulang ke coffee shop atau kedai kopi tersebut. Pernyataan ini didukung oleh Morais, tahun; dalam Sangadji \& Sopiah (2013), keduanya menyatakan bahwa loyalitas pelanggan merupakan komitmen pelanggan pada brand, store, atau supplier yang tercermin melalui consistent repurchase.

Penelitian sebelumnya yang dilakukan oleh Shin, Hwang, Lee, \& Cho (2015) meneliti dampak dari kualitas dan atmosphere coffee shop terhadap kepuasan dan loyalitas pelanggan pada 482 coffee shop waralaba di Korea. Hasil penelitiannya menunjukkan bahwa store atmosphere adalah salah satu variabel yang memengaruhi loyalitas pelanggan. Penelitian lain oleh Agustin, Azhad, \& Santoso (2019) di Warung Kopi Cak Wang Banyuwangi juga menunjukkan bahwa atmosfer kafe berpengaruh positif dan signifikan terhadap loyalitas pelanggan.

Selain itu, penelitian sebelumnya yang membahas tentang store atmosphere dan loyalitas pelanggan juga pernah dilakukan oleh Karim, Sepang, \& Soepeno (2020). Penelitian tersebut membahas pengaruh relationship marketing dan suasana kafe terhadap loyalitas pelanggan di Rumah Kopi Billy Kawasan Megamas. Hasil penelitiannya menunjukkan bahwa secara parsial suasana kafe berpengaruh positif dan signifikan terhadap loyalitas pelanggan di Rumah Kopi Billy Kawasan Megamas. Hal serupa juga diteliti oleh Rorimpandey, Sepang, \& Arie (2017) di Café Black Cup Coffee \& Roastery. Hasil penelitiannya menunjukkan bahwa berdasarkan hasil uji hipotesis ditemukan bahwa store atmosphere memiliki pengaruh positif dan signifikan terhadap loyalitas konsumen di Café Black Cup Coffee \& Roastery. Ada juga penelitian Gunawan, Fathorrahman, \& Handoko (2019) yang menunjukkan bahwa store atmosphere di Vosco Coffee memiliki dampak yang sangat besar terhadap loyalitas pelanggan. 
Peluang besar yang ada pada industri kopi, disertai dengan persaingan yang ketat dalam industri ini, membuat industri kopi menjadi kian menarik untuk diteliti. Penelitian ini bertujuan untuk mengetahui store atmosphere dan loyalitas pelanggan pada lima coffee shop di kota Bandung, seberapa besar pengaruh store atmosphere terhadap loyalitas pelanggan, dan apakah ada perbedaan loyalitas pelanggan pada coffee shop tersebut. Melalui hasil penelitian yang didapat, peneliti berharap memeroleh suatu gambaran bagaimana store atmosphere yang telah diciptakan oleh kelima coffee shop di kota Bandung, yang dianggap telah berhasil menarik minat masyarakat. Selanjutnya, gambaran ini diharapkan dapat menjadi masukan bagi para pebisnis kopi agar bisa bersaing dalam industri ini. Penelitian ini juga diharapkan dapat memberi masukan bagi kelima coffee shop ini, sehingga tetap bisa memertahankan citranya sebagai coffee shop yang dinilai menarik bagi masyarakat.

Gambar 3 menjelaskan bahwa penelitian ini mengadaptasi indikator-indikator penelitian sebelumnya. Elemen dalam store atmosphere yang berdasarkan Berman \& Evans (2010) dinilai tepat untuk menjadi indikator dalam penelitian ini, sebab telah digunakan dalam beberapa penelitian sebelumnya yang juga membahas store atmosphere, seperti penelitian Dessyana (2010); Fuad (2010); Purnamasari \& Hidayat (2016); Katarika \& Syahputra (2017); Syarif \& Oktafani (2017); serta Samboro, Budiarti, \& Santoso (2019). Sementara itu, indikator untuk loyalitas pelanggan menurut Tjiptono (2005), dalam Sangadji \& Sopiah (2013) sudah digunakan dalam beberapa penelitian lain, seperti Purnamasari \& Hidayat (2016); Nyonyie, Kalangi, \& Tamengkel (2019); serta Tarigan, Manurung, \& Marpaung (2019).

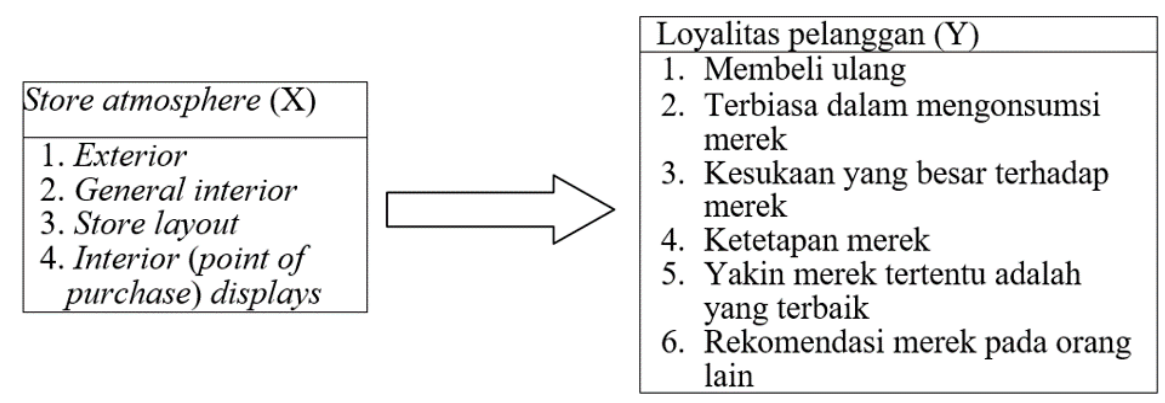

Gambar 3. Rerangka pemikiran

Sumber: Berman \& Evans (2010); Tjiptono (2005), dalam Sangadji \& Sopiah (2013)

Berdasarkan latar belakang tersebut, peneliti mengajukan hipotesis yang akan dibuktikan melalui penelitian ini, yaitu:

a. Ho: Tidak terdapat pengaruh store atmosphere terhadap loyalitas pelanggan pada coffee shop di kota Bandung.

H1:Terdapat pengaruh store atmosphere terhadap loyalitas pelanggan pada coffee shop di kota Bandung.

b. Ho:Tidak ada perbedaan loyalitas pelanggan pada coffee shop di kota Bandung.

H1:Ada perbedaan loyalitas pelanggan pada coffee shop di kota Bandung.

\section{METODE}

Metode yang digunakan dalam penelitian kali ini adalah metode kuantitatif dengan jenis penelitian deskriptif-kausalitas. Pengambilan sampel dengan metode non-probabilty sampling jenis purposive sampling, dengan jumlah responden pada penelitian ini sebanyak 20 orang di tiap 5 coffee shop atau kedai kopi. Teknik analisis data yang digunakan adalah analisis deskriptif, analisis regresi sederhana, dan one way anova dengan bantuan SPSS 24.0.

Analisis deskriptif digunakan peneliti untuk menganalisis atau menggambarkan store atmosphere dan loyalitas pelanggan. Sementara, analisis regresi sederhana peneliti gunakan untuk mengukur seberapa besar pengaruh antara store atmosphere dan loyalitas pelanggan, serta yang terakhir, one way anova digunakan untuk menguji rerata lebih dari dua sampel apakah berbeda secara signifikan atau tidak. 


\section{HASIL DAN PEMBAHASAN}

\subsection{Uji Validitas dan reliabilitas}

Uji validitas terhadap semua instrumen variabel store atmosphere $(\mathrm{X})$ dan variabel loyalitas pelanggan (Y) menunjukkan bahwa semua instrumen kedua variabel tersebut dinyatakan valid. Hal ini karena dari uji validitas yang dilakukan peneliti, total Pearson correlation pada masing-masing pernyataan lebih besar dari $r_{\text {tabel }}$ yaitu sebesar 0,195, dengan $n=100$ dan taraf signifikan 5\%. Menurut Kurniawan (2014), setiap pertanyaan dalam kuesioner dianggap valid apabila item pernyataan tersebut memiliki nilai lebih dari $r_{\text {tabel. }}$.

Sementara itu, berdasarkan data yang diperoleh dari Tabel 1 tentang hasil uji reliabilitas pada variabel store atmosphere dan loyalitas pelanggan, kedua variabel dinyatakan reliable. Hasil kedua variabel tersebut sebesar 0,686 dan 0,734, yang artinya lebih besar dari syarat suatu variabel dinyatakan reliable, yaitu 0,6 menurut Kurniawan (2014).

Tabel 1. Uji reliabilitas variabel store atmosphere dan loyalitas pelanggan

\begin{tabular}{ccc}
\hline Variabel & Cronbach's alpha & Nof items \\
\hline Store atmosphere & 0,686 & 20 \\
Loyalitas pelanggan & 0,734 & 6 \\
\hline
\end{tabular}

Sumber: Hasil pengolahan SPSS (2020)

\subsection{Tanggapan responden terhadap kedua variabel}

Tanggapan responden sebagai gambaran store atmosphere dan loyalitas pelanggan coffee shop di Bandung, dapat diamati dalam bentuk garis kontinum di bawah ini:

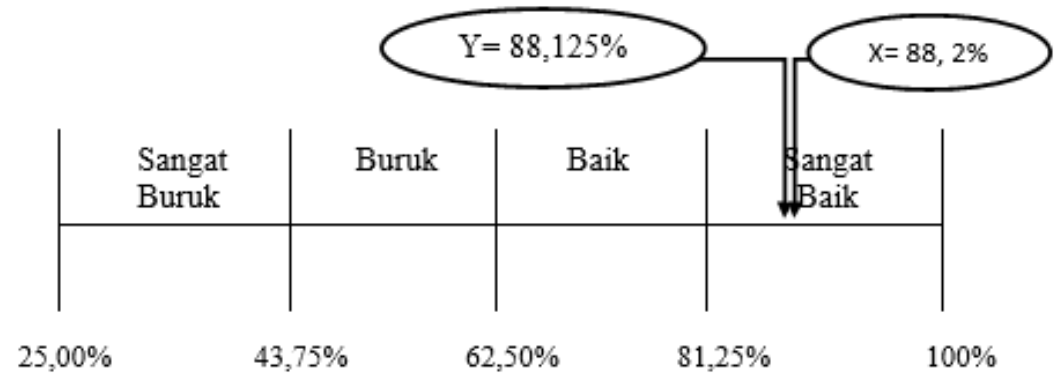

Gambar 4. Posisi store atmosphere (X) dan loyalitas pelanggan (Y) pada garis kontinum Sumber: Hasil pengolahan data peneliti (2020)

Berdasarkan tanggapan responden, variabel store atmosphere (X) secara keseluruhan tergolong dalam kategori sangat baik. Melalui Gambar 4 dapat diketahui bahwa skor total yang diperoleh variabel store atmosphere yaitu sebesar 88,2\%. Di antara 20 buah pernyataan mengenai store atmosphere, pernyataan yang mendapat skor tertinggi adalah "Melihat tampilan menu makanan dan minuman coffee shop atau kedai kopi membuat saya tertarik mencobanya" dengan persentase sebesar 92,25\% dan termasuk ke dalam kategori sangat baik. Sementara itu, terdapat pernyataan lain yang meskipun masih termasuk dalam kategori sangat baik, pernyataan tersebut mendapat skor terendah, yaitu "Bagian depan coffee shop atau kedai kopi menarik perhatian saya sebagai pengunjung" dengan persentase sebesar $84,75 \%$.

Berdasarkan tanggapan responden, variabel loyalitas pelanggan (Y) secara keseluruhan tergolong dalam kategori sangat baik, dapat dilihat dari Gambar 4 bahwa skor total yang diperoleh adalah sebesar $88,125 \%$. Hasil ini menunjukkan bahwa pemilihan kelima coffee shop sebagai tempat penelitian dinilai tepat, mengingat bahwa harapan dari hasil penelitian ini dapat memberi gambaran bagi para pebisnis kopi agar bisa bersaing dalam industri ini, serta dapat menjadi masukan bagi kelima coffee shop yang diteliti untuk memertahankan citranya. Hasil ini membuktikan anggapan yang benar bahwa kelima coffee shop tersebut dinilai telah memiliki citra yang baik di mata pelanggan untuk bisa loyal, yang juga sesuai dengan apa yang direkomendasikan oleh artikel dari Cosmopolitan Indonesia.

Di antara keenam pernyataan mengenai variabel loyalitas pelanggan, pernyataan yang mendapat 
skor tertinggi adalah "Saya menetapkan coffee shop atau kedai kopi tersebut sebagai pilihan saya untuk berkunjung", yaitu dengan skor sebesar 90,25\% dan termasuk ke dalam kategori sangat baik. Sementara itu, terdapat pernyataan lain yang meskipun masih termasuk dalam kategori sangat baik, pernyataan tersebut mendapat skor terendah, yaitu "Saya melakukan 2-3 kali pembelian ulang kembali di coffee shop atau kedai kopi" dan "Saya meyakini bahwa merek coffee shop atau kedai kopi tersebut adalah yang terbaik dibanding coffee shop atau kedai kopi lainnya" dengan persentase sebesar 86,5\%.

\subsection{Uji asumsi klasik}

Hasil uji normalitas Kolmogrov-Smirnov Test pada Tabel 2, menunjukkan nilai asymp. sig sebesar 0,200. Hasil ini lebih besar dari 0,05, yang artinya data tersebut terdistribusi dengan normal. Hal ini juga dapat dibuktikan dengan melihat pada Tabel 2, terdapat pernyataan bahwa test distribution is normal yang berarti data-data tersebut terdistribusi dengan normal.

Tabel 2. Hasil uji normalitas

\begin{tabular}{lc}
\hline & Unstandardized residual \\
\hline Asymp. sig. (2-tailed) & $0,200^{\mathrm{a}}$ \\
\hline
\end{tabular}

a. Test distribution is normal.

Sumber: Hasil pengolahan SPSS (2020)

Dari output Tabel 3, dapat dilihat bahwa nilai signifikan (linierity) sebesar 0,000 dan nilai signifikan (deviation from linierity) sebesar 0,242. Karena nilai signifikan kurang dari 0,05 (melihat dari nilai sig. linierity) dan lebih besar dari 0,05 (melihat dari nilai sig. deviation from linierity), maka dapat disimpulkan bahwa antara store atmosphere dengan loyalitas pelanggan terdapat hubungan yang linier.

Tabel 3. Hasil uji linieritas

\begin{tabular}{lllc}
\hline & & & Sig. \\
\hline Loyalitas pelanggan & Between & Linearity & 0,000 \\
Store atmosphere & groups & Deviation from linearity & 0,242 \\
\hline Sure
\end{tabular}

Sumber: Hasil pengolahan SPSS (2020)

Selanjutnya dari output Tabel 4, dapat dilihat bahwa korelasi antara store atmosphere dengan unstandardized residual memiliki nilai signifikan sebesar 0,194. Nilai ini lebih besar dari 0,05, sehingga dapat disimpulkan bahwa tidak terjadi masalah heterokedasitas, namun telah terjadi homokedasitas.

Tabel 4. Hasil uji heterokedasitas

\begin{tabular}{lccc}
\hline & & & Store atmosphere \\
\hline Spearman's rho & Unstandardized residual & Sig. (2-tailed) & 0,194 \\
\hline
\end{tabular}

Sumber: Hasil pengolahan SPSS (2020)

\subsection{Analisis regresi sederhana}

Untuk mengetahui adanya pengaruh antara store atmosphere terhadap loyalitas pelanggan, dilakukan analisis regresi sederhana, yang dirumuskan dengan model sebagai berikut.

$$
\mathbf{Y}=\mathbf{a}+\mathbf{b} . \mathbf{X}
$$

Keterangan:

Y: nilai dari variabel terikat (loyalitas pelanggan)

a: konstanta, yaitu nilai $\mathrm{Y}$ jika $\mathrm{X}=0$

b: koefisien regresi

$\mathrm{X}$ : nilai variabel bebas (store atmosphere)

Hasil output ditunjukkan pada Tabel 5, yang menunjukkan nilai konstanta dan koefisien regresi, sehingga dapat dibentuk persamaan regresi sederhana sebagai berikut:

$$
Y=-2,294+0,332 X
$$


Tabel 5. Hasil uji regresi linear sederhana

\begin{tabular}{lc}
\hline & Unstandardized coefficients \\
& $\mathrm{B}$ \\
\hline (Constant) & $-2,294$ \\
Store atmosphere & 0,332 \\
\hline
\end{tabular}

Sumber: Hasil pengolahan SPSS (2020)

\subsection{Hubungan dan pengaruh store atmosphere terhadap loyalitas pelanggan}

Bedasarkan hasil dari skor total perhitungan deskriptif sebelumnya di atas, dapat dilihat pengaruh setiap dimensi dari store atmosphere terhadap loyalitas pelanggan. Dimensi dengan nilai skor total tertinggi atau paling berpengaruh adalah dimensi interior (point of purchase) display dengan persentase sebesar $92,25 \%$, kedua adalah dimensi general interior (interior umum) dengan persentase sebesar $88,45 \%$, dan ketiga adalah dimensi store layout (tata letak toko) dengan persentase sebesar 88,3\%. Untuk dimensi yang memiliki skor total terendah yaitu dimensi exterior (bagian luar toko) dengan persentase sebesar 87,04\%. Dari hasil tersebut, dapat disimpulkan bahwa masing-masing dimensi memiliki pengaruh yang besar terhadap loyalitas pelanggan.

Peneliti melakukan analisis korelasi (r) dan koefisien determinasi $\left(\mathrm{r}^{2}\right)$ guna mengetahui hubungan dan pengaruh store atmosphere terhadap loyalitas pelanggan. Berikut Tabel 6 yang merupakan hasil dari olah data penelitian ini.

Tabel 6. Hasil korelasi dan koefisien determinasi

\begin{tabular}{cc}
\hline $\mathrm{R}$ & $R$ square \\
\hline $0,623^{\mathrm{a}}$ & 0,388 \\
\hline
\end{tabular}

Sumber: Hasil pengolahan SPSS (2020)

Pada Tabel 6 dapat dilihat bahwa nilai korelasi adalah 0,623, yang berarti bahwa tingkat hubungan antara store atmosphere dengan loyalitas pelanggan dapat dinyatakan kuat. Berikutnya, setelah memeroleh nilai korelasi, guna mengetahui seberapa besar pengaruh store atmosphere (X) terhadap loyalitas pelanggan $(\mathrm{Y})$, peneliti menghitung dengan menggunakan rumus koefisien determinasi menurut Kurniawan (2014), yaitu:

$$
\begin{aligned}
\mathrm{KD} & =\mathrm{r}^{2} \times 100 \% \\
& =(0,623)^{2} \times 100 \% \\
& =38,8129 \% \text { atau } 38,8 \% \text { (dibulatkan) }
\end{aligned}
$$

Nilai koefisien determinasi sebesar 38,8\% menunjukkan bahwa store atmosphere berpengaruh sebesar 38,8\% terhadap loyalitas pelanggan. Sedangkan sisanya sebesar $61,2 \%$ (didapat dari $100 \%$ $38,8 \%$ ) dipengaruhi oleh faktor-faktor lain dalam loyalitas pelanggan. Misalnya dalam penelitian Rorimpandey dkk. (2017), yang memiliki fokus penelitian serupa dengan penelitian ini, menunjukkan bahwa keanekaragaman produk juga merupakan salah satu faktor penting agar konsumen loyal terhadap produk yang ditawarkan. Sementara itu, penelitian serupa lainnya dari Gunawan dkk. (2019) menyimpulkan bahwa selain store atmosphere, kualitas produk Vosco Coffee memiliki dampak yang sangat besar terhadap loyalitas pelanggan. Ada juga penelitian Shin et al. (2015) pada 482 waralaba coffee shop di Korea, yang menunjukkan bahwa selain store atmosphere, ternyata taste, assurance and empathy, trust, reactivity, serta corporeality juga memengaruhi loyalitas pelanggan.

\subsection{Uji t}

Hasil uji t pada Tabel 7 menunjukkan diperolehnya $t$ hitung sebesar 7,886. Sementara itu, nilai $t$ tabel pada $\alpha=0,05$ adalah 1,660, yang berarti nilai t hitung lebih besar dari $t$ tabel ( $t$ hitung $>t$ tabel). Pada Tabel 7 juga tampak nilai signifikan adalah 0,000 atau kurang dari 0,05, sehingga peneliti memutuskan untuk menolak $\mathrm{H} 0$ dan menerima $\mathrm{H} 1$, artinya store atmosphere $(\mathrm{X})$ berpengaruh secara signifikan terhadap loyalitas pelanggan (Y) coffee shop atau kedai kopi di Bandung. Hal ini sejalan dengan penelitian Purnamasari \& Hidayat (2016). 
Tabel 7. Hasil uji t

\begin{tabular}{lcc}
\hline & $\mathrm{t}$ & Sig. \\
\hline Store atmosphere & 7,886 & 0,000 \\
\hline Sumber: Hasil pengolahan SPSS $(2020)$ &
\end{tabular}

Sumber: Hasil pengolahan SPSS (2020)

\subsection{One-way anova}

Nilai hasil uji one way anova dengan menggunakan SPSS ver 24 for Windows untuk penelitian ini, dapat dilihat dalam Tabel 8 berikut:

Tabel 8. Hasil one way anova

$\frac{\mathrm{F}}{\text { Between groups } 1,828}$

Hipotesis pada pengujian one way anova ini, adalah:

- Jika H0 diterima: Tidak ada perbedaan loyalitas pelanggan pada coffee shop di kota Bandung.

- Jika Ha diterima: Ada perbedaan loyalitas pelanggan pada coffee shop di kota Bandung.

Berdasarkan data pada Tabel 8, dapat dilihat bahwa nilai $\mathrm{F}$ hitung adalah 1,828. Hal ini menunjukkan bahwa nilai $\mathrm{F}$ hitung lebih kecil dari $\mathrm{F}$ tabel $(1,828<3,94)$, sehingga peneliti menyimpulkan untuk menerima HO dan menolak Ha. Dengan menerima H0, dapat disimpulkan bahwa meskipun loyalitas pelanggan telah dinilai sangat baik, namun tidak ada perbedaan store atmosphere terhadap loyalitas pelanggan pada coffee shop di kota Bandung.

\section{SIMPULAN DAN SARAN}

Berdasarkan hasil penelitian, peneliti mengambil beberapa simpulan untuk menjawab tujuan penelitian. Pertama, tanggapan responden mengenai store atmosphere coffee shop di Bandung secara kesuluruhan berada pada kategori sangat baik karena memiliki persentase sebesar $88,2 \%$. Hal ini menunjukkan bahwa semua elemen dalam variabel store atmosphere, yaitu bagian dari luar toko (exterior), interior umum (general interior), tata letak dalam toko (store layout), dan interior (point of purchase) display berada pada kategori sangat baik menurut responden.

Berikutnya yang kedua, tanggapan responden mengenai loyalitas pelanggan coffee shop di Bandung berada pada kategori sangat baik karena memiliki persentase sebesar $88,125 \%$. Hal ini menunjukkan bahwa semua dimensi yang berada pada variabel loyalitas pelanggan seperti (1) membeli ulang, (2) terbiasa dalam mengonsumsi merek, (3) kesukaan yang besar terhadap merek, (4) ketetapan merek, (5) yakin merek tertentu adalah yang terbaik, dan (6) rekomendasi merek pada orang lain dengan nilai sangat baik.

Selanjutnya yang ketiga, store atmosphere berpengaruh sebesar 38,8\% terhadap loyalitas pelanggan pada coffee shop di Bandung, sedangkan 61,2\% sisanya dipengaruhi oleh faktor-faktor lain. Terakhir, berdasarkan uji one way anova kepada 20 orang responden pada lima coffee shop atau kedai kopi di Bandung yang menjadi sampel penelitian, yaitu AC, K2, KK, SC, dan CB, dapat disimpulkan bahwa tidak ada perbedaan loyalitas pelanggan pada coffee shop di kota Bandung.

Bagi kelima coffee shop atau kedai kopi di Bandung, yaitu AC, K2, KK, SC, dan CB sudah dalam kategori sangat baik untuk store atmosphere dan loyalitas pelanggan. Hal ini didukung dengan masuknya lima coffee shop atau kedai kopi ini dalam sebuah artikel pada website majalah fashion terkenal di Indonesia, mengenai coffee shop di Bandung yang membuat nyaman untuk hang out. Akan tetapi, peneliti mengajukan beberapa saran bagi perusahaan untuk meningkatkan store atmosphere dan loyalitas pelanggan. Yang pertama, dari sisi exterior, item pertama memiliki skor terendah, yaitu mengenai "Bagian depan coffee shop atau kedai kopi menarik perhatian saya sebagai pengunjung". Oleh sebab itu, bagian depan lima coffee shop atau kedai kopi di Bandung perlu diperbaiki agar tidak terlihat samar-samar, sehingga menarik perhatian pelanggan dari jauh. Pelanggan akan tertarik untuk datang dan melihat ke dalam coffee shop atau kedai kopi tersebut. 
Peneliti juga menyarankan untuk sisi general interior dalam merchandise (barang dagangan) coffee shop. Berdasarkan hasil penelitian, item ketiga belas memiliki skor terendah, yaitu mengenai "Coffee shop atau kedai kopi memiliki produk makanan dan minuman yang enak". Oleh sebab itu, untuk kelima coffee shop atau kedai kopi di Bandung diharapkan agar meningkatkan cita rasa produk makanan dan minuman yang enak, sehingga menarik perhatian pengujung dan tercipta loyalitas pelanggan. Selanjutnya saran ketiga, dari sisi store layout, dalam tata letak barang-barang. Item kesembilan belas memiliki skor terendah, yaitu mengenai "Tata letak barang-barang dalam coffee shop atau kedai kopi sudah sangat baik". Oleh sebab itu, bagi lima coffee shop atau kedai kopi di Bandung tersebut, diperlukan penataan ulang agar terlihat estetik dan rapih untuk dilihat para pelanggan yang datang.

Sementara untuk sisi loyalitas pelanggan, kedua item yaitu keduapuluh satu dan keduapuluh lima memiliki skor terendah, yaitu mengenai "Saya melakukan 2-3 kali pembelian ulang kembali di coffee shop atau kedai kopi tersebut" dan mengenai "Saya meyakini bahwa merek coffee shop atau kedai kopi tersebut adalah yang terbaik dibanding coffee shop atau kedai kopi lainnya". Meskipun secara keseluruhan loyalitas pelanggan dapat dikatakan sudah termasuk dalam kategori sangat baik, peneliti menyarankan kelima coffee shop tersebut hanya perlu meningkatkan dalam hal pengenalan merek, guna memertahankan maupun meningkatkan loyalitas pelanggan. Peneliti menyarankan agar kelima coffee shop dapat mengadakan promosi yang akan berguna untuk pengenalan merek, hal ini juga dapat menarik pelanggan untuk datang lagi dan melakukan pembelian ulang. Selain itu, diperlukan juga peningkatan dalam hal pelayanan yang ramah, perbaikan, serta pembaharuan elemen-elemen store atmosphere, agar mendapatkan pelanggan baru dan terutama dapat memertahankan pelanggan yang sudah loyal ke coffee shop atau kedai kopi tersebut.

Selanjutnya yang kelima, dari hasil analisis one way anova yang dilakukan, dapat disimpulkan bahwa secara keseluruhan tidak ada perbedaan loyalitas pelanggan coffee shop di Bandung. Oleh sebab itu, diperlukan adanya keunikan yang berbeda dari store atmosphere (suasana toko) pada tiap lima coffee shop yang menjadi tempat penelitian, serta bagi para pebisnis kopi yang ingin membangun coffee shop. Hal ini perlu dilakukan agar pelanggan merasakan suasana toko yang berbeda dari coffee shop atau kedai kopi lainnya. Hal ini bisa menjadi keunikan dari coffee shop atau kedai kopi tersebut.

Terakhir, bagi para pebisnis kopi atau newcomers (pendatang baru), meminum kopi memang sudah menjadi trend di kalangan masyarakat, terutama anak muda. Namun, di samping membeli cita rasa kopi, pelanggan juga membeli suasana (store atmosphere) coffee shop tersebut. Oleh karena itu, para pebisnis kopi perlu memerhatikan store atmosphere seperti kelima coffee shop dalam penelitian ini, atau bahkan memunculkan konsep unik berbeda dari yang lain. Dan juga bagi yang tertarik ingin berbisnis kopi, perlu dipikirkan secara matang untuk dapat terjun ke bisnis ini. Karena, di tengah maraknya bisnis kopi yang sedang menjamur, jika pebisnis tidak bisa menarik loyalitas pelanggan, maka mereka tidak bisa bertahan dalam persaingan di industri kopi ini. Oleh karena itu, para pebisnis perlu memerhatikan dimensi-dimensi dalam store atmosphere seperti yang dibahas dalam penelitian ini, untuk menarik loyalitas pelanggan. Store atmosphere tidak hanya bicara tentang menciptakan suasana tempat yang memberikan kenyamanan kepada konsumen, tetapi bagaimana meningkatkan penjualan dan mendapatkan loyalitas dari konsumen.

Untuk penelitian selanjutnya dengan topik yang serupa, peneliti menyarankan agar menggunakan metodologi penelitian dan obyek penelitian yang berbeda, agar dapat dilihat perbedaan dan persamaan antara penelitian ini dengan penelitian selanjutnya. Penelitian selanjutnya juga sebaiknya perlu menambahkan jumlah indikator pertanyaan kuesioner, antara variabel X (store atmosphere) dan $\mathrm{Y}$ (loyalitas pelanggan) agar tidak jauh berbeda. Peneliti mengggunakan indikator pertanyaan dalam kuesioner penelitian ini sebanyak 20 buah item untuk variabel $\mathrm{X}$ (store atmosphere), sedangkan variabel Y (loyalitas pelanggan) hanya 6 buah item. Jadi, secara perbandingan jumlah pertanyaan dalam kuesioner, hal ini kurang dapat menggambarkan perbandingan variasi yang baik antar variabel. Saran selanjutnya, karena penelitian ini hanya meneliti tentang perbandingan pengaruh store atmosphere terhadap loyalitas pelanggan pada coffee shop di kota Bandung, maka untuk penelitian selanjutnya disarankan untuk meneliti faktor-faktor lainnya dalam loyalitas pelanggan, di luar variabel store atmosphere, misalnya minat beli konsumen, kepuasan konsumen, keputusan pembelian, dan lain-lain. 


\section{ACKNOWLEDGEMENTS}

Artikel ini merupakan bagian dari skripsi yang telah disusun oleh peneliti selama berkuliah di Universitas Telkom. Peneliti ingin mengucapkan terima kasih kepada responden yang telah bersedia mengisi kuesioner untuk penelitian ini. Peneliti juga mengucapkan terima kasih kepada chief in editor, editor, serta reviewer Jurnal Manajemen Maranatha, atas kesempatan yang diberikan kepada peneliti untuk menerbitkan artikel ini. Terakhir, terimakasih juga peneliti sampaikan kepada semua pihak yang memberi dukungan kepada peneliti dari awal penyusunan penelitian ini, hingga selesai sampai dengan memublikasikan artikel ini.

\section{REFERENSI}

Agustin I., Azhad, M. N., \& Santoso, B. (2019). Product diversity, atmosfer kafe dan harga dampaknya terhadap loyalitas pelanggan Warung Kopi Cak Wang Banyuwangi. Jurnal Penelitian Ipteks, 4(1), 63-78. Diperoleh dari http://jurnal.unmuhjember.ac.id/index.php/zPENELITIAN_IPTEKS/article/ download/2110/1737.

Andri, Y. D. P. (2019, September 30). Indonesia terpilih sebagai ketua dewan organisasi kopi internasional. Bisnis.com. Diperoleh dari https://ekonomi.bisnis.com/read/20190930/12/1153708/ indonesia-terpilih-sebagai-ketua-dewan-organisasi-kopi-internasional/.

Berman, B. R., \& Evans, J. R. (2010). Retail management: A strategic approach. $11^{\text {th }}$ Edition. United State of America: Pearson Education, Inc.

Citta, G. D. (2019, April 19). 5 coffee shop di Bandung yang bikin betah untuk nongkrong. Cosmopolitan Indonesia. Diperoleh dari https://www.cosmopolitan.co.id/article/read/4/2019/15737/5-coffee-shop-di-bandung-yang-bikinbetah-untuk-nongkrong.

Dessyana, C. J. (2010). Store atmosphere pengaruhnya terhadap keputusan pembelian konsumen di Texas Chicken Multimart II Manado. Jurnal EMBA: Jurnal Riset Ekonomi, Manajemen, Bisnis dan Akuntansi, 1(3), 844-852. Diperoleh dari https://ejournal.unsrat.ac.id/index.php/emba/ article/view/ $1893 /$.

Fuad, M. (2010). Store atmosphere dan perilaku pembelian konsumen di Toko Buku Gramedia Malang. Jurnal Manajemen Pemasaran Modern, 2(1), 1-13. Diperoleh dari https://www.onlinejournal.unja.ac.id/pemasaran/article/view/28/18.

Gunawan, T., Fathorrahman, \& Handoko, Y. (2019). Efek mediasi kepuasan pelanggan atas pengaruh kualitas produk dan store atmosphere terhadap loyalitas pelanggan. Jurnal Manajemen \& Kewirausahaan, 7(2), 189-204. Diperoleh dari http://jurnal.unmer.ac.id/index.php/jmdk/article/ download/3347/pdf.

Karim, D., Sepang, J. L., \& Soepeno, D. (2020). Pengaruh relationship marketing dan suasana kafe terhadap loyalitas pelanggan di Rumah Kopi Billy Kawasan Megamas. Jurnal EMBA: Jurnal Riset Ekonomi, Manajemen, Bisnis dan Akuntansi, 8(1), 136-145. Diperoleh dari https://ejournal.unsrat. ac.id/index.php/emba/article/download/27361/26919.

Katarika, D. M., \& Syahputra. (2017). Pengaruh store atmosphere terhadap keputusan pembelian pada coffee shop di Bandung. Jurnal Ecodemica, 1(2), 162-171. Diperoleh dari https://ejournal.bsi.ac.id/ ejurnal/index.php/ecodemica/article/download/1566/pdf.

Kementrian Pertanian. (2017). Outlook 2017: Komoditas pertanian sub sektor perkebunan kopi. Jakarta: Pusat Data dan Sistem Informasi Pertanian, Sekretariat Jendral-Kementrian Pertanian.

Kurniawan, A. (2014). Metode riset untuk ekonomi dan bisnis: Teori, konsep, dan praktik penelitian bisnis (dilengkapi perhitungan pengolahan data dengan IBM SPSS 22.0). Bandung: Alfabeta.

Larasati, R. A. (2019, Oktober 18). Ekspor kopi Indonesia turun, apa sebabnya?. Kompas.com. Diperoleh dari https://money.kompas.com/read/2019/10/18/224300926/ekspor-kopi-indonesiaturun-apa-sebabnya.

Monicasef. (2019, Oktober 25). Kedai kopi, bisnis masa kini, menjanjikan di masa depan. Suara.com. Diperoleh dari https://www.suara.com/yoursay/2019/10/25/065000/kedai-kopi-bisnis-masa-kinimenjanjikan-di-masa-depan/.

Nyonyie, R. A., Kalangi, J. A. F., \& Tamengkel, L. F. (2019). Pengaruh kualitas produk terhadap loyalitas pelanggan kosmetik Wardah di Transmart Bahu Manado. Jurnal Administrasi Bisnis, 9(3), 18-24. Diperoleh dari https://ejournal.unsrat.ac.id/index.php/jab/article/download/25123/24822.

Purnamasari, N. D., \& Hidayat, A. (2016). Analisis pengaruh store atmosphere terhadap loyalitas pelanggan pada Warung Misbar Bandung tahun 2016. Jurnal e-Proceeding of Applied Science, 2(2), 441-447. Diperoleh dari https://openlibrary.telkomuniversity.ac.id/pustaka/files/116965/jurnal 
_eproc/analisis-pengaruh-store-atmosphere-terhadap-loyalitas-pelanggan-pada-warung-misbarbandungtahun-2016.pdf/.

Pusparisa, Y. (2019, Desember 13). 10 negara dengan konsumsi kopi terbesar dunia. Databoks. Diperoleh dari https://databoks.katadata.co.id/datapublish/2019/12/13/10-negara-dengan-konsumsikopi-terbesar-dunia/.

Rorimpandey, J. N., Sepang, J. L., \& Arie, F. V. (2017). Analisis pengaruh store atmosphere dan keanekaragaman produk terhadap loyalitas konsumen di Café Black Cup Coffee \& Roaster. Jurnal EMBA: Jurnal Riset Ekonomi, Manajemen, Bisnis dan Akuntansi, 5(2), 893-900. Diperoleh dari https://ejournal.unsrat.ac.id/index.php/emba/article/download/16006/15515.

Samboro, J., Budiarti, L., \& Santoso, E. B. (2019). Pengaruh store atmosphere terhadap keputusan pembelian dan dampaknya terhadap loyalitas pelanggan Toko Buku Togamas Malang. Jurnal Administrasi dan Bisnis, 13(1), 75-82. Diperoleh dari http://j-adbis.polinema.ac.id/index.php/adbis/ article/view/67/65.

Sangadji, E. M., \& Sopiah. (2013). Perilaku konsumen: Pendekatan praktis disertai himpunan jurnal penelitian. Yogyakarta: Andi.

Shin, C. S., Hwang, G. S., Lee, H. W., \& Cho, S. R. (2015). The impact of Korean franchise coffee shop service quality and atmosphere on customer satisfaction and loyalty. The East Asian Journal of Business Management, 5(4), 47-57. doi: 10.13106/eajbm.2015.vol5.no4.47.

Sujana, A. (2012). Manajemen minimarket. Jakarta: Raih Asa Sukses (Penebar Swadaya Grup).

Syarif, F. F., \& Oktafani, F. (2017). Analisis perbandingan persepsi konsumen mengenai store atmosphere pada Selaz Café \& Resto dan Arosa Café \& Resto Sumedang. Jurnal Buana Ilmu, 1(2), 230-238. Diperoleh dari https://journal.ubpkarawang.ac.id/index.php/BuanaIlmu/article/view/142/.

Tarigan, H. I., Manurung, Y. S., \& Marpaung, W. (2019). Loyalitas pelanggan dan kualitas pelayanan pada pelanggan jasa transportasi online. Philanthrophy Journal of Psychology, 3(1), 1-74. Diperoleh dari http://journals.usm.ac.id/index.php/philanthropy/article/download/1285/984/. 